3 Ashworth A. Principles of criminal law. Oxford: Clarendon, 1995:169 on.

P R FERGUSON

Department of Law, University of Dundee

\section{Why causing death is not necessarily morally equivalent to allowing to die - a response to Ferguson}

SIR

Dr Randall's conclusion that causing death is not necessarily morally equivalent to permitting it is entirely correct but it is not based on sound reasoning.' If a patient in the permanent vegetative state (PVS) is nourished there is an obvious intention that he or she should live. If that nutrition is withdrawn there is an even more certain intention that he or she should die.

Causing the death of the PVS patient by withdrawing nutrition is intentional in a way that causing death by double effect is not. Dr Randall is presumably neither surprised nor displeased when analgaesia which might shorten life actually prolongs desired pain-free life. Those who withdraw nutrition from PVS patients would be both surprised and displeased if doing so did not shorten life in the PVS. In one case analgaesia is wanted but in the other death.

Nor is it morally relevant that the PVS patient dies of the disease after the withdrawal of nutrition. Otherwise a doctor could decline to ventilate or stop ventilating a patient with recoverable acute polyneuritis and then claim that the patient was killed by the disease not the doctor. A doctor is morally (and usually legally) responsible for all that he or she does, stops doing or decides not to do. The moral difference between the polyneuritis and the PVS patients is that the former should be kept alive and the latter should not.

The law recognises this by declaring that at a certain point in time the nutrition of PVS patients ceases to be a benefit to them and therefore the duty of care to provide it also ceases.

There is a moral difference between deliberate killing on the one hand and causing death by double effect, by inaction or by stopping action on the other hand, even though the motive is benefit to the patient in each case. The difference lies in the damaging extended effect of allowing doctors to kill deliberately by direct action. For example progress in Dr Randall's own specialty of palliative medicine might be impeded.

\section{References}

1 Randall F. Why causing death is not necessarily morally equivalent to allowing to die - a response to Ferguson. fournal of Medical Ethics 1997;23:373-6.

A B SHAW

2 The Stables, Weeton Lane, Harewood, Leeds, LS17 9LP

\section{The ethics of human cloning}

SIR

Harris ${ }^{1}$ in his recent article in the journal rightly decries the lack of carefully reasoned debate on the ethics of human cloning. In drawing attention to the use of nuclear transfer and embryo-splitting technology as differing little from sporadic monozygotic twinning and currently utilised in vitro embryo biopsy techniques, many of the stated ethical concerns surrounding cloning appear diminished if not unsubstantiated.

However, in suggesting that the central principle of Kantian ethics, that an individual should not be considered in terms of his or her utility but always primarily in terms of his or her intrinsic worth, as seldom helpful in debate in this area, he is too dismissive. A fundamental difference between sexual and asexual reproduction (as represented by cloning) is that in the latter a substantial proportion of the individual's makeup can be predicted and anticipated. Environmental influences certainly guarantee that phenotypic duplication is very unlikely to be achievable but nevertheless the influence of genetic factors on physiology and behaviour, particularly those associated with complex traits, are frequently underestimated. If cloning technology was to be employed so as to create an individual genetically identical to that of a pre-existing person, there is no entailment of a breach of one of the central tenets of Kantian thought - that we always treat people as ends in themselves and never merely as means. Sexual reproduction, of course, does not prevent prospective parents or society from being motivated by the expected utility of a fetus or child, but the intrinsic genetic randomness of the process all but denies any guarantee of the desired outcome. In contrast cloning promises considerable success in this respect and may present the greatest opportunity so far in history actually to treat people merely means and not as ends.

Interventions such as currently used techniques in prenatal diagnosis, cluding genetic analysis by embryo biopsy, are an exception to this rule. We can predict and determine the nature $f$ the being brought into existence. $\mathcal{F}_{\mathrm{n}}$ these instances, however, the motigation for the test ie the utility being attached to the presence or absence of a discrete disease or condition, is ove stated and open to societal sanction (for example testing for Down's syndrorax, spina bifida, cystic fibrosis) or not (sex selection for sociocultural reasor The limits of infraction of the Kantian principle can thus be determined. The replication of genetically identical ind viduals, however, presents the og ortunity for abuse, since the motivation for employing such a mode of repEিduction need not be overtly stated afld can easily escape critical examination by society. Open critical examinationtof the basis by which genetic traits selected for is necessary if doctors are escape the all-to-familiar accusation $\delta f$ pursuing some eugenic agenda. \&use clearly, human reproduction is not presently free of breaches of central tenet (for instance prograwnes aimed at the intrauterine diagnosis azd subsequent destruction of fetuses wh Down's syndrome), but the introd $\overline{\text { pC- }}$ tion of cloning would remove the possibility for the critical ethical sc tiny that such decisions demand.

Harris goes on to offer a framew $\bar{F}$ k of reproductive autonomy as a phipsophical basis on which to devetop ethical approaches to questions suth as these. In the particular instaree stated above (asexual reproduction ${ }_{\text {of }}$ human beings prescient of the en phenotype of the "parent") no pubjic legislative, ethical or medical body could safeguard the ethical use of cloning technology when the motiotions of parents remain opaque afld the consequences for the individgal who results are considerable. Despite the many conceivable meritorims grounds for use of this technology $13 \mathrm{r}$ reproduction the grounds for a probibition on cloning, at least in this context, seem strong.

\section{Acknowledgement}

Thanks to Julian Savulescu for use discussions on this topic.

\section{References}

1 Harris J. "Goodbye Dolly?" The ethilcs of human cloning. Fournal of Medieal Ethics 1997;23:353-60. 